\title{
Science wins over creationism in South Korea
}

\section{Government asks publishers to retain examples of evolution in science textbooks.}

\section{Soo Bin Park}

06 September 2012

South Korea's government has urged textbook publishers to ignore calls to remove two examples of evolution from high-school textbooks.

The move follows a campaign earlier this year by the Society for Textbook Revise (STR), which argued that details about the evolution of the horse and of the avian ancestor Archaeopteryx should be removed from the books (see 'South Korea surrenders to creationist demands').

The STR, an offshoot of the Korea Association for Creation Research, says that students should learn "various" theories about the development of life on Earth. It argued that the textbooks used flawed examples of evolution that are under debate by evolutionary scientists.

In May, news emerged that publishers were planning to drop the offending sections, sparking outrage among some scientists. The resulting furore prompted the government to set up an 11-member panel, led by the Korean Academy of Science and Technology (KAST) and including five experts on evolution and fossils, to oversee science-textbook revisions (see 'Expert panel to guide science-textbook revisions in South Korea').

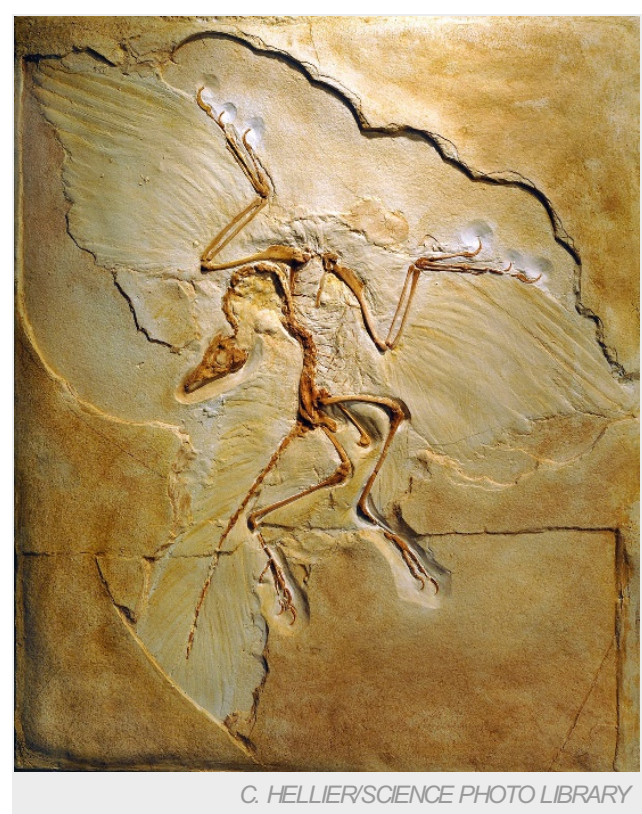

Archaeopteryx will once again grace the pages of Korean science textbooks.

On 5 September, the panel concluded that Archaeopteryx must be included in Korean science textbooks, and it reaffirmed that the theory of evolution is an essential part of modern science that all students must learn in school.

The panel emphasized that ongoing scientific debate about whether Archaeopteryx gave rise to all birds or is just one example of a feathered dinosaur does not undermine the theory of evolution itself. Indeed, the panel says, it is important to mention the existence of many ornithological fossils that could be intermediate species between dinosaurs and birds.

The panel accepted that the textbooks' explanation of the evolution of the horse was too simplistic and should be revised or replaced with a different example, such as the evolution of whales. The government has backed the panel's conclusions, and textbook publishers will be asked to report on how they have implemented these revisions before the new books are rolled out to schools in 2013.

The STR responded to the news by claiming that the government showed bias in excluding STR members from the expert panel, and says that it will keep fighting for "better" science textbooks.

Duckhwan Lee, president of the Basic Science Council and the panel leader, says he hopes that the panel's guidance will eventually improve the public's understanding of evolution. In July, a survey by Gallup Korea, a research firm based in Seoul, found that of 613 respondents, $45 \%$ believed in evolution and $32 \%$ believed in creationism.

Lee says that he is glad that the STR's campaign has provided an opportunity to improve science textbooks. "We welcome any petition in the future," he says, "if it is regarding flaws in the evolution parts of science textbooks. But we do not want to waste our time if it has any religious implication."

Nature | doi:10.1038/nature.2012.11377 